\title{
Synthesis of 2,6-disubstituted tetrahydroazulene derivatives
}

\author{
Zakir Hussain ${ }^{* 1,2}$, Henning Hopf ${ }^{1}$, Khurshid Ayub ${ }^{2}$ and S. Holger Eichhorn ${ }^{3}$
}

\section{Full Research Paper}

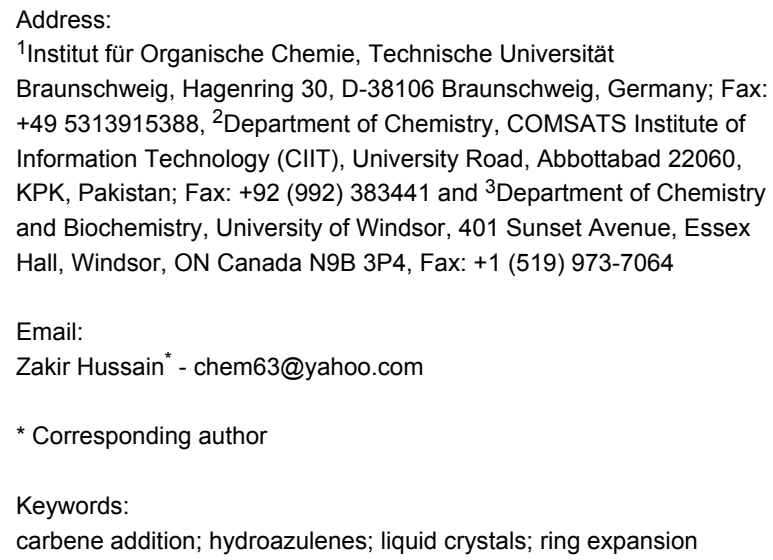

Beilstein J. Org. Chem. 2012, 8, 693-698. doi:10.3762/bjoc. 8.77

Received: 16 December 2011

Accepted: 17 April 2012

Published: 04 May 2012

This article is part of the Thematic Series "Progress in liquid crystal chemistry II".

Guest Editor: S. Laschat

(C) 2012 Hussain et al; licensee Beilstein-Institut. License and terms: see end of document.

\begin{abstract}
Synthesis of hydroazulene derivatives has been carried out through a ring-enlargement route by using carbene adduct intermediates. The protocol can be applied for the construction of functionalized hydroazulene skeletons as key components of many natural products as well as the core system of novel liquid-crystalline materials.
\end{abstract}

\section{Introduction}

Hydroazulene skeletons provide the basic ring systems of natural products, such as guaianolide sesquiterpenes [1,2] and the so-called furanether B series $[3,4]$. The stereoselective synthesis of trans-hydroazulene derivatives by a tandem Michael/ intramolecular Wittig approach was reported previously [5]. Recently, a new synthetic method for the construction of a hydroazulene skeleton by a $[5+2]$ cycloaddition reaction was also developed [6]. Additionally, there have been many reports on the synthesis of 2,6-disubstituted azulenes [7,8]. In 1951, the ring expansion of indanes was reported for the synthesis of such systems, but it delivered only very low yields [9]. We recently employed [10,11] the method reported by Keehn et al. [12] using Birch reduced indanes for the synthesis of 2,6-disubstituted perhydroazulene systems as core elements of novel liquidcrystalline (LC) materials.

As far as mesogenic compounds are concerned, there is still a growing need for more new derivatives to be synthesised and tested for features desirable for novel displays, which include, but are not limited to, lower driving voltages, lower power consumption and faster response times. In contrast to the core system presently used in most nematic LC materials, our new 
core based on perhydroazulenes showed [13], e.g., improved properties regarding phase-transition temperatures. Therefore, due to its potential use as a subsystem of many natural products, as well as as the core moiety for novel LC materials, further investigation on perhydroazulene-based substrates and synthetic intermediates is desirable.

\section{Results and Discussion}

The synthesis of various intermediates and the final hydroazulene derivatives $\mathbf{9}$ and $\mathbf{1 0}$ is described in this section. 2-Indancarboxylic acid (1) [14] was reduced under Birch conditions [15] to 4,7-dihydro-2-indancarboxylic acid (2) as the kinetically controlled product. In order to carry out carbene additions to the obtained 1,4-cyclohexadiene system, esterification [16] of 2 was carried out in a one-pot procedure in DMF at $40{ }^{\circ} \mathrm{C}$ with 1,1'-carbonyldiimidazole, tert-butyl alcohol and DBU to afford ester $\mathbf{3}$ in quantitative yield. The ester $\mathbf{3}$ was then subjected to carbene addition by treatment with ethyl diazoacetate in the presence of a copper catalyst [17] in THF under reflux. The carbene adduct 4 was obtained as the major product, as a colorless oil in acceptable yields (55-60\%, Scheme 1$)$. In addition to 4, we were able to isolate the side product 5 in ca. $10 \%$ yield. The formation of carbene adduct $\mathbf{4}$ from 2-indancarboxylic acid (1) can also be followed from the previous work [18] Evidently, in the formation of the adduct, the carbene attacks the central double bond of the substrate.
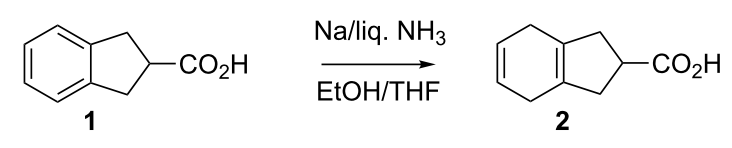

\section{1. $(\mathrm{Im})_{2} \mathrm{CO}, \mathrm{DMF}$ \\ 2. $t-\mathrm{BuOH} / \mathrm{DBU}$}<smiles>CC(C)(C)OC(=O)C1CC2=C(CC=CC2)C1</smiles>

$\frac{\mathrm{N}_{2} \mathrm{CHCO}_{2} \mathrm{Et}}{\mathrm{Cu}(\mathrm{acac})_{2} / \mathrm{THF}}$

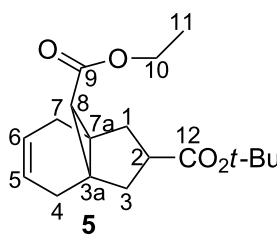

Scheme 1: Preparation of carbene adducts 4 [18] and 5.
The complete characterization of intermediates $\mathbf{2}$ and $\mathbf{3}$ and carbene adduct 4 was carried out by NMR and related analytical techniques, similar to previous reports [18], while the 3D structure of $\mathbf{4}$ was further established based on the X-ray data of its derivative 6 [20].

It is important to note that the addition resulted in higher yields when the length of time used for the addition of the ethyl diazoacetate was extended, which was again similar to our earlier investigations [10]. The formation of only one major isomer (4) in this case could be due to the greater steric hindrance for carbene addition to the inner carbon-carbon double bond, in spite of the fact that the central olefinic double bond is more electron-rich and, hence, in principle more susceptible to such additions. In order to elucidate the configuration of $\mathbf{4}$, ester cleavage with formic acid was carried out resulting in the acid $\mathbf{6}$ as a colorless solid, which was recrystallized from hexane and dichloromethane to afford single crystals suitable for X-ray analysis. The X-ray data [20] showed that the central, sixmembered ring is almost planar but is slightly folded about the axis $C(2) \cdots C(6)$; the five-membered ring is essentially planar. The two larger rings are approximately coplanar, but the threeand six-membered rings form an interplanar angle of $78.4(1)^{\circ}$. The atoms of the ester side chain are coplanar and this plane forms a dihedral angle of $78.73(4)^{\circ}$ with the central ring. In the crystal, the molecules form hydrogen-bonded dimers across inversion centers. Furthermore, a triplet in the ${ }^{1} \mathrm{H}$ NMR spectrum at $\delta=1.54 \mathrm{ppm}$ with a coupling constant of $4.2 \mathrm{~Hz}$ between the $\mathrm{H}$-atoms at the cyclopropyl ring, indicates an antirelation between the ethoxycarbonyl group and the cyclohexene ring.

The subsequent step comprised the ring opening of $\mathbf{4}$ to furnish the cycloheptatrienes $\mathbf{7}$ and $\mathbf{8}$. The carbene adduct $\mathbf{4}$ was first treated with bromine leading to the formation of the corresponding dibromide, which was then followed by elimination with triethylamine to afford triethylamine hydrobromide alongside the formation of a norcaradiene intermediate in situ, which was transformed into the 2,6-disubstituted tetrahydroazulene 7 as a viscous oil. It is important to note that tetrahydroazulenes, in contrast to perhydroazulenes, are not very resistant towards dehydrogenation (oxidation) and, when kept at room temperature for a few days, form the corresponding azulenes (giving a bluish color).

It is worth mentioning that in our earlier work on similar compounds [19], we isolated at least two isomers of $\mathbf{4}$ (with the methine hydrogen atom at the five-membered ring being present at either the $\alpha$ or $\beta$ position). In our earlier work [10], carbene addition to similar compound(s) was found to give a mixture of stereoisomers. However, in the present case, we were only able to isolate 4 as a single stereoisomer. Furthermore, the procedure for the synthesis of compounds $\mathbf{4}$ and $\mathbf{5}$ is essentially the same as described previously for analogous compounds [10].
Similar to our earlier investigations [10], various isomers could be formed through the rearrangement of double bonds in the seven-membered ring of 7. However, through the NMR data of 7, we saw the formation of an isomer with double bonds at the ring junction as a major isomer. Formation of one major isomer under the given conditions could be explained through the 
hydrogen shifts of cycloheptatrienes by the so-called Berson-Willcott rearrangement [21]. We assume that bromination $\left(\mathrm{Br}_{2}\right)$ and dehydrobromination $\left(\mathrm{Et}_{3} \mathrm{~N}\right)$ of 4 resulted in the formation of an intermediate, which converted to 7 through thermal disrotatory electrocyclic ring opening and a basecatalyzed prototropic shift. The ester 7 underwent acidcatalyzed hydrolysis (formic acid) to afford $\mathbf{8}$ as a solid, which on recrystallization resulted in single crystals suitable for X-ray analysis (Scheme 2).

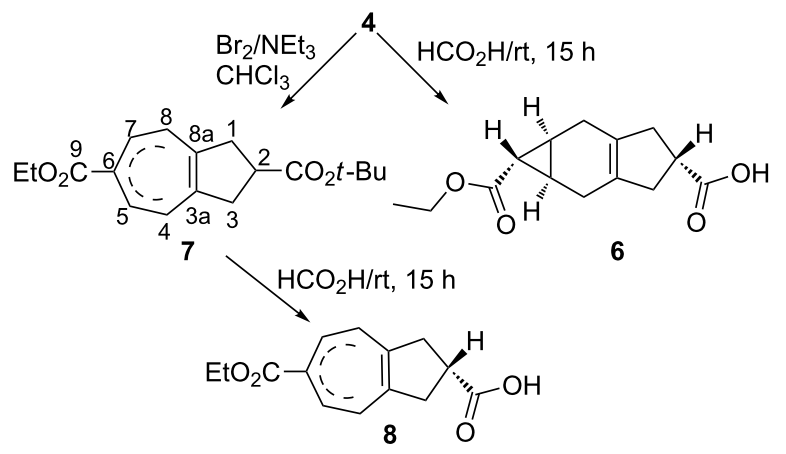

Scheme 2: Preparation of the cycloheptatrienes 7 and $8[18,20]$.

The structural analysis of $\mathbf{8}$ revealed [22] an azulene framework that is partially hydrogenated to a cyclopentane subunit in places where molecules are slightly disordered in the lattice. These molecules represent the slightly torsionally distorted enantiomers of $\mathbf{8}$. At this stage we did not find any hydrogen atom at position 6; however, additional $\mathrm{H}$-atoms at $\mathrm{C}(4)$ and $\mathrm{C}(8)$, each with only $50 \%$ occupancy, were found. Acid $\mathbf{8}$ was further condensed [23] with $p$-cyanophenol in the presence of $\mathrm{SOCl}_{2}$ and DMAP in dichloromethane to obtain the corresponding ester. The GC analysis of the product mixture indicated the presence of two isomers (ratio 3:1), which were later separated through reversed-phase HPLC $\left(\mathrm{MeOH} / \mathrm{H}_{2} \mathrm{O} 3: 1\right)$ and characterized as derivatives $\mathbf{9}$ and $\mathbf{1 0}$ (Scheme 3).

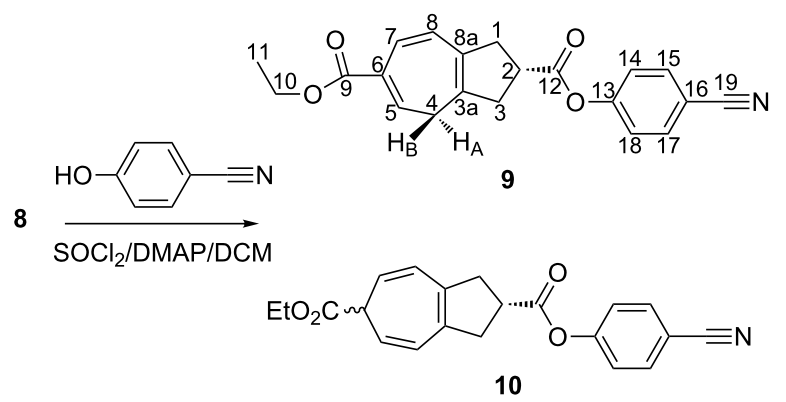

Scheme 3: Preparation of derivatives 9 and $\mathbf{1 0}$
The cycloheptatriene unit of 9 adopts, in sterically relaxed systems, a boat-like conformation, whereas its planar form represents the transition state of the thermal boat-inversion process. Additionally, since $\mathbf{8}$ and $\mathbf{9}$ possess a center of chirality at $\mathrm{C}(2)$, there are two different boat conformations of the cycloheptatriene unit possible, namely those in which $\mathrm{C}(4)$ is on the same or on the opposite side with respect to the substituent at $\mathrm{C}(2)$. The ${ }^{1} \mathrm{H}$ NMR spectrum $\left(400 \mathrm{MHz}, \mathrm{CDCl}_{3}\right.$ ) of 9 displays diastereotopic (syn and anti to the ester group) $\mathrm{H}$-atoms at $\mathrm{C}(4)$, indicating that the ring-inversion process is still slow at the temperature of the measurement, but the observed dd signals already show some line broadening.

Structure elucidation of compounds $\mathbf{9}$ and $\mathbf{1 0}$ was carried out by 1D and 2D NMR spectroscopy. Most ${ }^{13} \mathrm{C}$-signals could be assigned through HMQC analysis. For quaternary carbons, analysis of HMBC data was sufficient to complete the assignment. In the ${ }^{1} \mathrm{H}$ NMR spectrum of compound 9, the $\mathrm{H}$-atom $\left(\mathrm{H}_{\mathrm{A}}\right.$ or $\left.\mathrm{H}_{\alpha}\right)$ at $\mathrm{C}(1)$ is located in the deshielding region of the carbonyl function and, hence, resonates slightly downfield (from its geminal $\mathrm{H}$-atom, $\mathrm{H}_{\mathrm{B}}$ ) at $\delta=2.94 \mathrm{ppm}$, together with the $\mathrm{H}$-atoms at $\mathrm{C}(3)$, whereas $\mathrm{H}_{\mathrm{B}}\left(\mathrm{H}_{\beta}\right)$ itself resonates at $\delta=$ $2.92 \mathrm{ppm}$. Furthermore, the $\mathrm{H}$-atom at $\mathrm{C}(2)$, being geminal to a strongly deshielding carboxylate group, gives a multiplet at $\delta=$ $3.49 \mathrm{ppm}$. Additionally, $\mathrm{H}$-atoms at $\mathrm{C}(14)$ and $\mathrm{C}(18)$ show a doublet at $\delta=7.22 \mathrm{ppm}(J=8.7 \mathrm{~Hz})$, which is acceptable for such protons after considering the effect of cyano and carboxylate groups on the respective positions of the aromatic ring. The doublet at $\delta=7.65 \mathrm{ppm}(J=8.7 \mathrm{~Hz})$, integrated for two protons, was assigned to the $\mathrm{H}$-atoms at $\mathrm{C}(15)$ and $\mathrm{C}(17)$. The most differentiated signals were identified for $\mathrm{H}$-atoms at $\mathrm{C}(4)$ giving two distinct dd at $\delta=2.50 \mathrm{ppm}(J=7.1,13.4 \mathrm{~Hz})$ and at $\delta=2.65 \mathrm{ppm}(J=7.5,13.5 \mathrm{~Hz})$. These values seem very reasonable considering the envelope form of the seven-membered ring, in which $\mathrm{C}(4)$ extends out of the plane of the ring thereby allowing the remaining six carbon atoms to enhance the delocalization. This six-carbon system in turns generates a ring current similar to benzene, though less pronounced, allowing $\mathrm{H}_{\mathrm{A}}$ to resonate in the deshielding region $(\delta=2.65 \mathrm{ppm})$ and $\mathrm{H}_{\mathrm{B}}$ in the shielding region $(\delta=2.50 \mathrm{ppm})$. The $\mathrm{H}$-atoms at positions $\mathrm{C}(5)$ and $\mathrm{C}(8)$ of the seven-membered ring (being almost in identical electronic environments), give a broad multiplet at $\delta=6.52 \mathrm{ppm}$. However, a pronounced doublet at $\delta=6.96 \mathrm{ppm}$ $(J=11.2 \mathrm{~Hz})$ is assigned for the hydrogen atom at position $\mathrm{C}(7)$ considering the effect of the nearby carboxylate group and several $\mathrm{sp}^{2}$-hybridized carbon atoms in its immediate vicinity on both sides.

In the case of compound 10, due to shifting of the double bonds, the single $\mathrm{H}$-atom at $\mathrm{C}(4)$ becomes olefinic (conjugated) thereby resonating together with $\mathrm{C}(8)$; it displays a doublet at 
$\delta=5.47 \mathrm{ppm}(J=9.2 \mathrm{~Hz})$. Similarly, the $\mathrm{H}$-atoms at $\mathrm{C}(5)$ and $\mathrm{C}(7)$ give dd at $\delta=6.22 \mathrm{ppm}(J=5.6,9.1 \mathrm{~Hz})$. The single proton at $\mathrm{C}(6)$ provides a triplet at $\delta=2.73 \mathrm{ppm}(J=5.6 \mathrm{~Hz})$ However, the exact stereochemistry at $\mathrm{C}(6)$ could not be established in the present case.

Finally, we investigated compounds $\mathbf{9}$ and $\mathbf{1 0}$ under a polarizing microscope for their textural features, and DSC experiments were carried out to determine the phase-transition temperatures. In the case of $\mathbf{9}$, the first melting-point peak in the DSC never recovered, but a very broad transition at $5{ }^{\circ} \mathrm{C}$ was observed subsequently indicating the possibility of a very exothermic process on cooling to $-40{ }^{\circ} \mathrm{C}$. Furthermore, after the first melting the sample was an isotropic liquid down to $0{ }^{\circ} \mathrm{C}$. The first melting showed complex behavior over a temperature range of $30^{\circ} \mathrm{C}$, and areas with Schlieren-like textures were present but were never recovered or reproduced. In the case of compound 10, the same behavior was observed. As we mentioned earlier, tetrahydroazulenes, in contrast to perhydroazulenes, are not very resistant against dehydrogenation (oxidation), and when kept at room temperature for a few days, they form the corresponding azulenes. Such an unusual behavior of compounds $\mathbf{9}$ and $\mathbf{1 0}$ can easily be attributed to their oxidation. Additionally, our earlier investigations on similar compounds $[10,13]$ showed that fully hydrogenated derivatives show pronounced mesogenic behavior.

\section{Experimental}

Thin-layer chromatography was performed by using precoated plastic plates, PolyGram Sil G/UV 254 . Column chromatography was performed on silica gel $60(70-230 \mathrm{mesh})$ from Merck (Darmstadt). HPLC analysis was carried out on a system consisting of Shimadzu (Duisburg, Germany), Gilson 305 pumps, a Shimadzu SPD-M10AV UV-vis detector, and a fraction collector. In the GC system, a Hewlett-Packard 6890 with a flame-ionization-detection (FID) system was used. All chromatograms were processed by ColaChrom software (Version 8.1) developed by MPI für Kohlenforschung, Mülheim, Germany. All organic solvents used in the study were HPLC grade and were purchased from Baker GmbH, Germany. The argon gas used was of high-purity grade. IR spectra were recorded using a Nicolet 320 FT-IR and a Bruker Tensor 27 spectrometer. Samples were prepared either as $\mathrm{KBr}$ pellets or as thin films. ${ }^{1} \mathrm{H}$ and ${ }^{13} \mathrm{C}$ NMR spectra were recorded on the following spectrometers: Bruker AC-200, ${ }^{1} \mathrm{H}$ NMR (200.1 MHz), ${ }^{13} \mathrm{C}$ NMR (50.3 MHz); Bruker DRX-400, ${ }^{1} \mathrm{H}$ NMR (400.1 MHz), ${ }^{13} \mathrm{C}$ NMR (100.6 MHz). Chemical shifts $(\delta)$ are expressed in parts per million $(\mathrm{ppm})$ downfield from tetramethylsilane or by using the residual nondeuterated solvent as the internal standard $\left(\mathrm{CDCl}_{3}:{ }^{1} \mathrm{H}, \delta=7.26 \mathrm{ppm} ;{ }^{13} \mathrm{C}\right.$, $\delta=77.00 \mathrm{ppm}$ ). Coupling constants are expressed in hertz.
Mass spectra were recorded by using a Finnigan MAT 8430 spectrometer using the electron-ionization method (EI, $70 \mathrm{eV}$ ). Synthesis and analytical data of compounds $2-\mathbf{4}$ and $\mathbf{6}$ can be found in the literature [18].

Ethyl 2-tert-butoxycarbonyl-2,3,4,7-tetrahydro-1 $\mathrm{H}$-3a,7amethanoinden-8-carboxylate (5): Compound 5 was obtained as a highly viscous, colorless oil in $10 \%$ yield during the synthesis of carbene adduct 4 as given in the literature [18]. $R_{\mathrm{f}} 0.41$ ( $\mathrm{SiO}_{2}$; hexane/ $\mathrm{CH}_{2} \mathrm{Cl}_{2}$ 1:1); IR (film): 2900 (m, CH-stretch), 1695 and $1700(\mathrm{~s}, \mathrm{C}=\mathrm{O}), 1340,1250,1133(\mathrm{~m}) \mathrm{cm}^{-1} ;{ }^{1} \mathrm{H}$ NMR $\left(200.1 \mathrm{MHz}, \mathrm{CDCl}_{3}\right) \delta 1.21\left(\mathrm{t},{ }^{3} J=7.1 \mathrm{~Hz}, \mathrm{H}-\mathrm{C}(11)\right)$, 1.31-1.40 (s, $\left.\mathrm{C}\left(\mathrm{CH}_{3}\right)_{3}\right), 1.55-1.68\left(\mathrm{~m}, \mathrm{CH}_{2}(1), \mathrm{CH}_{2}(3)\right), 1.62$ (br s, H-C(8)), 2.31 (br s, $\mathrm{CH}_{2}(4), \mathrm{CH}_{2}(7)$ ), 2.78-2.81 (m, $\mathrm{H}-\mathrm{C}(2)), 4.08$ (q, $\left.J=7.1 \mathrm{~Hz}, \mathrm{CH}_{2}(10)\right), 5.49$ ppm (br s, H-C(5), $\mathrm{H}-\mathrm{C}(6)) ;{ }^{13} \mathrm{C}$ NMR (50.3 MHz, $\mathrm{CDCl}_{3}$ ) $\delta 14.1$ (q, C(11)), 27.80 (q, $\left.\mathrm{C}\left(\mathrm{CH}_{3}\right)_{3}\right), 29.41(\mathrm{~d}, \mathrm{C}(8)), 31.23$ (t, $\left.\mathrm{C}(4), \mathrm{C}(7)\right), 34.31$ (s, $\mathrm{C}(3 \mathrm{a}), \mathrm{C}(7 \mathrm{a})), 38.23$ (d, C(2)), 42.68 (d, C(1), C(3)), 61.01 (t, $\mathrm{C}(10)), 80.12\left(\mathrm{~s}, \mathrm{C}\left(\mathrm{CH}_{3}\right)_{3}\right), 125.60(\mathrm{~d}, \mathrm{C}(5), \mathrm{C}(6)), 171.84$, 172.01 (s, C(9), C(12)); EIMS m/z: $306\left(8, \mathrm{M}^{+}\right), 249$ (57, [M $\left.\left.\mathrm{C}_{4} \mathrm{H}_{9}\right]^{+}\right), 205\left(80,\left[\mathrm{M}-\mathrm{C}_{5} \mathrm{H}_{9} \mathrm{O}_{2}\right]^{+}\right), 132(100,[205-$ $\left.\left.\mathrm{C}_{3} \mathrm{H}_{5} \mathrm{O}_{2}\right]^{+}\right)$; HRMS $(\mathrm{m} / z)$ : $[\mathrm{M}]^{+}$calcd for $\mathrm{C}_{18} \mathrm{H}_{26} \mathrm{O}_{4}$, 306.183109 ; found, $306.183123+1.1 \mathrm{ppm}$.

6-Ethyl-tetrahydroazulene-2-carboxylate (8): To a stirred solution of $4(3.06 \mathrm{~g}, 0.01 \mathrm{~mol})$ in $\mathrm{CHCl}_{3}(100 \mathrm{~mL})$, a solution of $\mathrm{Br}_{2}(0.6 \mathrm{~mL}, 0.01 \mathrm{~mol})$ in $\mathrm{CHCl}_{3}(5 \mathrm{~mL})$ was added dropwise at $0{ }^{\circ} \mathrm{C}$. When the addition was complete, triethylamine (6.91 mL, $49.71 \mathrm{mmol})$ was added. Triethylamine hydrobromide began to form immediately. The mixture was heated under reflux for $18 \mathrm{~h}$. After cooling, the hydrobromide was filtered off. The filtrate was evaporated and the resulting oil partitioned between benzene and dilute aqueous acid $(\mathrm{HCl})$. The benzene layer was washed with water, dried with $\mathrm{MgSO}_{4}$ and filtered, and the solvent was removed. The reaction mixture was filtered through a small column of silica gel, eluting with pentane and dichloromethane (1:2). After evaporation of the solvent the crude product 7 was obtained as a viscous bluish oil $(2.6 \mathrm{~g}$, $85 \%$ ). The preparation of compound 7 is analogous to that described in [10]. The crude intermediate 7 was not purified further and was subjected to hydrolysis directly: A solution of 7 $(1.0 \mathrm{~g}, 3.29 \mathrm{mmol})$ in formic acid $(100 \mathrm{~mL})$ was stirred at $\mathrm{rt}$ for $15 \mathrm{~h}$. The solvent was removed under reduced pressure and the crude product was recrystallized from hexane and dichloromethane to give $0.71 \mathrm{~g}(85 \%)$ of $\mathbf{8}$ as slightly bluish needles. $R_{\mathrm{f}}$ $0.35\left(\mathrm{SiO}_{2} ; \mathrm{EtOAc} / \mathrm{CH}_{2} \mathrm{Cl}_{2}\right.$ 1:5); IR (film): 2913 (m, $\mathrm{CH}$, stretch.), 1712, 1718 (s, C=O), 1320, 1150 (m) cm ${ }^{-1} ;{ }^{1} \mathrm{H}$ NMR $\left(200.1 \mathrm{MHz}, \mathrm{CDCl}_{3}\right) \delta 1.29\left(\mathrm{t},{ }^{3} J=7.1 \mathrm{~Hz}, \mathrm{CH}_{3}(12)\right)$, 2.80-3.27 (m, $\left.\mathrm{CH}_{2}(1), \mathrm{CH}_{2}(3), \mathrm{H}-\mathrm{C}(2)\right), 4.18$ (q, $J=7.1 \mathrm{~Hz}$, $\left.\mathrm{CH}_{2}(11)\right), 2.60-2.75 / 5.48-6.69$ ppm $(2 \times \mathrm{m}, 5 \mathrm{H}$, sevenmembered ring-H); $\left.{ }^{13} \mathrm{C} \mathrm{NMR} \mathrm{(50.3} \mathrm{MHz,} \mathrm{CDCl}_{3}\right) \delta 14.21$ (q, 
C(12)), $27.50(t), 37.53(t), 39.39(t), 41.97(d), 60.79$ (d, $\mathrm{C}(11)), 117.87$ (d), 124.60 (d), 126.61 (d), 130.61 (d), 133.99 (s), 132.70 (s), 166.81, $181.41 \mathrm{ppm}(\mathrm{s}, \mathrm{C}(9), \mathrm{C}(10))$; EIMS m/z: $248\left(19, \mathrm{M}^{+}\right), 219\left(59,\left[\mathrm{M}-\mathrm{C}_{2} \mathrm{H}_{5}\right]^{+}\right), 203(18,[\mathrm{M}-$ $\left.\left.\mathrm{C}_{2} \mathrm{H}_{5} \mathrm{O}\right]^{+}\right), 175\left(72,\left[\mathrm{M}-\mathrm{C}_{3} \mathrm{H}_{5} \mathrm{O}_{2}\right]^{+}\right), 129(100,[175-$ $\left.\left.\mathrm{HCO}_{2} \mathrm{H}\right]^{+}\right)$; $\operatorname{HRMS}(\mathrm{m} / z)$ : $[\mathrm{M}]^{+}$calcd for $\mathrm{C}_{14} \mathrm{H}_{16} \mathrm{O}_{4}$, 248.104859; found, $248.104835+0.96 \mathrm{ppm}$.

1,2,3,4-Tetrahydroazulene-2,6-dicarboxylic acid 2-(4-cyanophenyl) ester 6-ethyl ester (9): Thionyl chloride $(0.021 \mathrm{~mL}$, $0.28 \mathrm{mmol})$ was added to a solution of $4-(N, N-$ dimethylamino)pyridine (34 $\mathrm{mg}, 0.27 \mathrm{mmol})$ in dichloromethane $(5 \mathrm{~mL})$ at $-20{ }^{\circ} \mathrm{C}$. Acid 8 (70 $\left.\mathrm{mg}, 0.28 \mathrm{mmol}\right)$ was added and the resulting solution was stirred for $1 \mathrm{~h}$. Then, 4 - $(N, N$-dimethylamino)pyridine $(34 \mathrm{mg}, 0.27 \mathrm{mmol})$ and the p-cyanophenol (31 mg, $0.30 \mathrm{mmol})$ in dichloromethane were added and the stirring was continued for another $1 \mathrm{~h}$. The mixture was washed with water $(5 \mathrm{~mL})$, and the organic layer was separated and dried with sodium sulfate to give a crude mixture of 9 and 10 (75 mg, 72\%). The product mixture was filtered through a small column of silica gel, eluting with pentane and dichloromethane (1:2), to remove impurities, and was further separated through reversed-phase HPLC. The analytical HPLC indicated the presence of both isomers $\mathbf{9}$ and $\mathbf{1 0}$ in a 3:1 ratio. For preparative HPLC, the sample was dissolved in $\mathrm{MeOH} /$ $\mathrm{CH}_{2} \mathrm{Cl}_{2}$, and $\mathrm{MeOH} / \mathrm{H}_{2} \mathrm{O}$ 75:25 (v/v) was used as a mobile phase. Compound 9 was isolated in $97 \%$ purity $\left(t_{\mathrm{R}} 4.40 \mathrm{~min}\right)$, while 10 was obtained in $94 \%$ purity $\left(t_{\mathrm{R}} 4.98\right) . \mathrm{R}_{\mathrm{f}} 0.32\left(\mathrm{SiO}_{2}\right.$; hexane $/ \mathrm{CH}_{2} \mathrm{Cl}_{2}$ 1:1); mp 83-84 ${ }^{\circ} \mathrm{C}$; IR (film): 2931 (m CH, stretch), 1705 and $1714 \mathrm{~s}(\mathrm{C}=\mathrm{O}), 1311,1230,1122(\mathrm{~m}) \mathrm{cm}^{-1}$; ${ }^{1} \mathrm{H}$ NMR (400.1 MHz, $\left.\mathrm{CDCl}_{3}\right) \delta 1.29\left(\mathrm{t},{ }^{3} J=7.1 \mathrm{~Hz}, \mathrm{CH}_{3}(11)\right)$, $2.50\left(\mathrm{dd}, J=7.1,13.4 \mathrm{~Hz}, \mathrm{H}_{\beta}(4)\right), 2.65(\mathrm{dd}, J=7.5,13.5 \mathrm{~Hz}$, $\left.\mathrm{H}_{\alpha}(4)\right), 2.92\left(\mathrm{~m}, \mathrm{CH}_{2}(3), \mathrm{H}_{\beta}(1)\right), 2.94$ (dd, $J=6.8,17.4 \mathrm{~Hz}$, $\left.\mathrm{H}_{\alpha}(1)\right), 3.49$ (m, H-C(2)), 4.21 (q, $\left.J=7.1 \mathrm{~Hz}, \mathrm{CH}_{2}(10)\right), 6.52$ (br. m, H-C(5), H-C(8)), 6.96 (d, J=11.2 Hz, H-C(7)), 7.22 (d, $J=8.7 \mathrm{~Hz}, \mathrm{H}-\mathrm{C}(14), \mathrm{H}-\mathrm{C}(18)), 7.65 \mathrm{ppm}(\mathrm{d}, J=8.7 \mathrm{~Hz}$, $\mathrm{H}-\mathrm{C}(15), \mathrm{H}-\mathrm{C}(17)) ;{ }^{13} \mathrm{C} \mathrm{NMR}\left(100.6 \mathrm{MHz}, \mathrm{CDCl}_{3}\right) \delta 14.01$ (q, $\mathrm{C}(11)), 27.26$ (t, C(4)), 37.43 (t, C(3)), 39.63 (t, C(1)), 42.01 (d, C(5)), 60.63 (t, C(10)), 109.49 (s, C(19)), 117.94 (s, C(16)), 122.39 (d, C(2)), 126.74 (d, C(8)), 128.50 (2 × d, C(15), (17)), 130.47 (d, C(7)), 130.81 (s, C(3a), 132.27 (s, C(8a)), 133.50 $(2 \times \mathrm{d}, \mathrm{C}(14), \mathrm{C}(18)), 133.61$ (, $\mathrm{C}(6)), 153.83$ (s, C(13)), 166.52 (s, C(9)), 172.76 ppm (s, C(12)); EIMS m/z: 349 (27, $\left.\left[\mathrm{M}^{+}\right]\right), 320\left(100,\left[\mathrm{M}-\mathrm{C}_{2} \mathrm{H}_{5}\right]^{+}\right), 304\left(17,\left[\mathrm{M}-\mathrm{C}_{2} \mathrm{H}_{5} \mathrm{O}\right]^{+}\right), 276$ $\left(18,\left[\mathrm{M}-\mathrm{C}_{3} \mathrm{H}_{5} \mathrm{O}_{2}\right]^{+}\right), 203\left(56,\left[\mathrm{M}-\mathrm{C}_{8} \mathrm{H}_{4} \mathrm{O}_{2} \mathrm{~N}\right]^{+}\right)$; HRMS $(m / z):[\mathrm{M}+\mathrm{Na}]^{+}$calcd for $\mathrm{C}_{21} \mathrm{H}_{19} \mathrm{NO}_{4} \mathrm{Na}, 372.120362$; found, $372.120629+0.72 \mathrm{ppm}$.

1,2,3,6-Tetrahydroazulene-2,6-dicarboxylic acid 2-(4-cyanophenyl) ester 6-ethyl ester (10): $R_{\mathrm{f}} 0.29\left(\mathrm{SiO}_{2} ;\right.$ hexane $/ \mathrm{CH}_{2} \mathrm{Cl}_{2}$ 1:1); mp 80-82 ${ }^{\circ} \mathrm{C}$; IR (film): 2927 (m, CH-stretch), 1703, 1712 (s, C=O), 1342, 1223, $1165(\mathrm{~m}) \mathrm{cm}^{-1} ;{ }^{1} \mathrm{H}$ NMR (400.1 MHz, $\left.\mathrm{CDCl}_{3}\right) \delta 1.29\left(\mathrm{t},{ }^{3} J=7.1 \mathrm{~Hz}, \mathrm{CH}_{3}(11)\right), 2.73(\mathrm{t}, J=5.6 \mathrm{~Hz}$, $\mathrm{H}-\mathrm{C}(6)), 3.16$ (m, $\left.\mathrm{CH}_{2}(1), \mathrm{CH}_{2}(3)\right), 3.42$ (m, H-C(2)), 4.25 (q, $J$ $\left.=7.1 \mathrm{~Hz}, \mathrm{CH}_{2}(10)\right), 5.47$ (d, J=9.2 Hz, H-C(4), H-C(8)), 6.22 $(\mathrm{dd}, J=5.6,9.1 \mathrm{~Hz}, \mathrm{H}-\mathrm{C}(5), \mathrm{H}-\mathrm{C}(7)), 7.23$ (d, $J=8.8 \mathrm{~Hz}$, H-C(15), H-C(17)), 7.69 (d, $J=8.8 \mathrm{~Hz}, \mathrm{H}-\mathrm{C}(14), \mathrm{H}-\mathrm{C}(18)$ ); ${ }^{13} \mathrm{C}$ NMR (100.6 MHz, $\left.\mathrm{CDCl}_{3}\right) \delta 14.0$ (q, C(11)), $39.24(\mathrm{t}$, $\mathrm{C}(1), \mathrm{C}(3)), 40.95$ (d, C(6)), 45.0 (d, C(2)), 60.9 (t, C(10)), 109.56 (s, C(19)), 117.94 (s, C(16)), $118.08(2 \times \mathrm{d}, \mathrm{C}(5), \mathrm{C}(7))$, $122.39(2 \times \mathrm{d}, \mathrm{C}(4), \mathrm{C}(8)), 124.28(2 \times \mathrm{d}, \mathrm{C}(15), \mathrm{C}(17)), 133.45$ $(2 \times \mathrm{d}, \mathrm{C}(14), \mathrm{C}(18)), 139.44(2 \times \mathrm{s}, \mathrm{C}(3 \mathrm{a}), \mathrm{C}(8 \mathrm{a})), 153.83$ (s, C(13)), 172.50 (s, C(9)), 172.80 ppm (s, C(12)); EIMS 349 (26, $\left.\left[\mathrm{M}^{+}\right]\right), 320\left(100,\left[\mathrm{M}-\mathrm{C}_{2} \mathrm{H}_{5}\right]^{+}\right), 304\left(16,\left[\mathrm{M}-\mathrm{C}_{2} \mathrm{H}_{5} \mathrm{O}\right]^{+}\right), 276$ $\left(16,\left[\mathrm{M}-\mathrm{C}_{3} \mathrm{H}_{5} \mathrm{O}_{2}\right]^{+}\right), 203\left(57,\left[\mathrm{M}-\mathrm{C}_{8} \mathrm{H}_{4} \mathrm{O}_{2} \mathrm{~N}\right]^{+}\right)$; HRMS $(m / z):[\mathrm{M}+\mathrm{Na}]^{+}$calcd for $\mathrm{C}_{21} \mathrm{H}_{19} \mathrm{NO}_{4} \mathrm{Na}, 372.120362$; found, $372.120630+1.05 \mathrm{ppm}$.

\section{Supporting Information}

\section{Supporting Information File 1}

DSC-data of isomers 9 and $\mathbf{1 0 .}$

[http://www.beilstein-journals.org/bjoc/content/

supplementary/1860-5397-8-77-S1.pdf]

\section{Acknowledgements}

Z. H. thanks Prof. Dr. Wolfgang Gärtner at the Max-Planck Institute for Bioinorganic Chemistry, Mülheim (Germany) for his support in purification and characterization all new substances in the present study.

\section{References}

1. Mehta, G.; Thomas, A. Synth. Commun. 1992, 22, 1831-1838.

2. Christie, J. J.; Varkey, T. E.; Whittle, J. A. J. Org. Chem. 1981, 46, 3590-3592. doi:10.1021/jo00331a002

3. Battaglia, R.; De Bernardi, M.; Fronza, G.; Mellerio, G.; Vidari, G.; Vita-Finsi, P. J. Nat. Prod. 1980, 43, 319-328. doi:10.1021/np50009a002

4. Price, M. E.; Schore, N. E. J. Org. Chem. 1989, 54, 5662-5667. doi:10.1021/jo00285a010

5. Fujimoto, T.; Uchiyama, Y.-k.; Kodama, Y.-i.; Ohta, K.; Yamamoto, I.; Kakehi, A. J. Org. Chem. 1993, 58, 7322-7323. doi:10.1021/jo00078a004

6. Mitachi, K.; Yamamoto, T.; Kondo, F.; Shimizu, T.; Miyashita, M.; Tanino, K. Chem. Lett. 2010, 39, 630-632. doi:10.1246/cl.2010.630

7. Ginsburg, D. Non-Benzenoid Aromatic Compounds; Interscience: New York, 1959.

8. Lloyd, D. The Chemistry of Conjugated Cyclic Compounds; Wiley: Chichester, 1989.

9. Plattner, P. A.; Fürst, A.; Müller, A.; Somerville, A. R. Helv. Chim. Acta 1951, 34, 971-988. doi:10.1002/hlca.19510340332

10. Hussain, Z.; Hopf, H.; Pohl, L.; Oeser, T.; Fischer, A. K.; Jones, P. G. Eur. J. Org. Chem. 2006, 5555-5569. doi:10.1002/ejoc.200500733 
11. Hussain, Z.; Hopf, H.; Eichhorn, H. S. Beilstein J. Org. Chem. 2012, 8, 403-410. doi:10.3762/bjoc.8.44

12. Luhowy, R.; Keehn, P. M. J. Am. Chem. Soc. 1977, 99, 3797-3805. doi:10.1021/ja00453a046

13. Hopf, H.; Hussain, Z.; Menon, R. S.; Raev, V.; Jones, P. G.; Pohl, L. M. Synlett 2011, 1273-1276. doi:10.1055/s-0030-1260551

14. Carlson, G. L. B.; Quina, F. H.; Zarnegar, B. M.; Whitten, D. G. J. Am. Chem. Soc. 1975, 97, 347-354. doi:10.1021/ja00835a021

15. Sundeen, J. E.; Reid, J. A.; Osband, J. A.; Hauck, F. P. J. Med. Chem. 1977, 20, 1478-1485. doi:10.1021/jm00221a023

16. Ohta, S.; Shimabayashi, A.; Aono, M.; Okamoto, M. Synthesis 1982, 833-834. doi:10.1055/s-1982-29961

17. Marchand, A. P.; Brockway, N. M. Chem. Rev. 1974, 74, 431-469. doi:10.1021/cr60290a002

18. Zindel, J.; Maitra, S.; Lightner, D. A. Synthesis 1996, 1217-1222. doi:10.1055/s-1996-4370

19. Hussain, Z.; Koley, D.; Hopf, H. Helv. Chim. Acta 2005, 88 , 3263-3272. doi:10.1002/hlca.200590262

20. Jones, P. G.; Hopf, H.; Hussain, Z. Acta Crystallogr. 2005, E61, o3034-03035. doi:10.1107/S1600536805026565

21. Berson, J. A.; Willcott, M. R., III. J. Am. Chem. Soc. 1966, 88, 2494-2502. doi:10.1021/ja00963a025

22. Hussain, Z.; Oeser, T.; Hopf, H. Acta Crystallogr. 2005, C61, o652-0653. doi:10.1107/S0108270105029744

23. Arrieta, A.; Garcia, T.; Palomo, C. Synth. Commun. 1982, 12, 1139-1146. doi:10.1080/00397918208065981

\section{License and Terms}

This is an Open Access article under the terms of the Creative Commons Attribution License

(http://creativecommons.org/licenses/by/2.0), which permits unrestricted use, distribution, and reproduction in any medium, provided the original work is properly cited.

The license is subject to the Beilstein Journal of Organic Chemistry terms and conditions:

(http://www.beilstein-journals.org/bjoc)

The definitive version of this article is the electronic one which can be found at: doi:10.3762/bjoc. 8.77 